\title{
Evaluation of fired clay bricks - extent of decay
}

\author{
Rörig-Dalgaard $\mathrm{I}^{\mathrm{a}}$, Charola $\mathrm{AE}^{\mathrm{b}}$ \\ a Technical Univeristy of Denmark, Department of Civil Engineering, Kgs. Lyngby, Denmark \\ b Museum Conservation Institute, Smithsonian Institution, Washington DC, USA
}

\begin{abstract}
A tool for evaluation of fired clay bricks is both valuable and necessary to assess the extent of decay. In the present study, a recently developed methodology was extended to make it more generally valid by increasing the variety of the test material. It was found that high deterioration depth in these non-homogeneously fired clay bricks, requires that both $\mathrm{pH}$ and silicon be measured, while for more traditional weathering of calcareous bricks $\mathrm{pH}$ measurements are sufficient to determine deterioration depth.
\end{abstract}

Keywords: fired non-calcareous clay bricks; extent of decay, pH, Si

\section{Introduction/Background}

For damage assessment, renovation and reuse of materials, an evaluation of the material is both valuable and necessary in order to make an accurate assessment when failure occurs, and to keep the material in construction for as long as possible. To assess the remaining service life, it is presently suggested [1-2] to use rather time and labour consuming methods that do not allow to follow the damage development as a function of distance from the exposed surface. In a previous study, preliminary results on new calcareous fired clay bricks [3] formed the basis for elaboration of a new methodology to overcome these issues. The methodology consists in steps with increasing laboratory demands: 1. Macro pictures; 2. Extraction of a core for pH measurements; 3. Study of cross sections; 4. Measurements of the Si content. To make the methodology more generally valid, the examinations are here extended to include two fired non-calcareous clay bricks, produced by Falkenlöwe and exposed on the ground for 10 years. The bricks were hand moulded and fired in a circular kiln with related variations [4], one bright (FB) and one dark (FD) coloured, presumably fired at a relatively low and high temperature, respectively. The aim is to develop a general grounded, objective evaluation method, which can reveal the deterioration depth thus allowing to define criteria for acceptable deterioration depth as suggested in Fig.1.

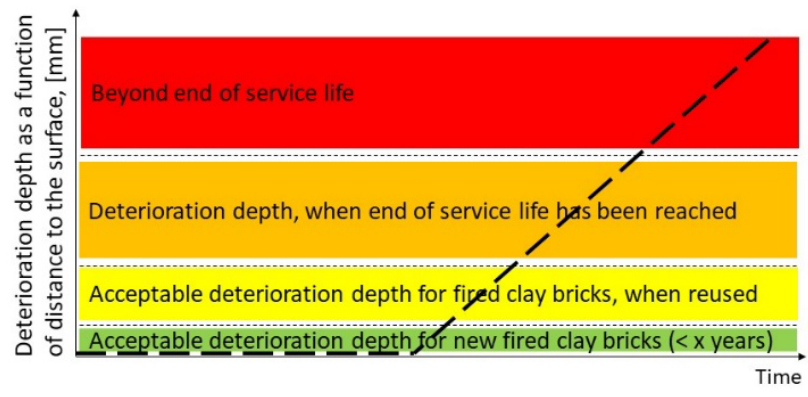

Figure 1. With time, materials will eventually degrade (dotted line) from the exposed face. The graph shows deterioration depth as a function of distance from the surface. The principle of acceptable deterioration depth related to: new bricks (green color), reuse (yellow), until end of service life (orange) and beyond end of service life (red) is shown. The principle is adapted from [5].

\section{Results and discussion}

Macro and stereomicroscope images are shown in Fig. 2 of FB (Fig. a-c) and FD (Fig. d-e). The macro image of FB-10 reveals clear surface deterioration of the original once plane surface. The cross section in fluorescent light (Fig 2b) further reveals a visibly increased area of air voids and a reduced amount of aggregates compared to the reference (Fig 2c). The green coloring at the outer left + top edges in Fig $2 b$ reveals deterioration in the perpendicular plane, also visible in Fig 2a. The same deterioration pattern is seen for FD-10 (Fig 2e +f), though to a lesser degree as the macro image does not reveal clear visual surface deterioration.
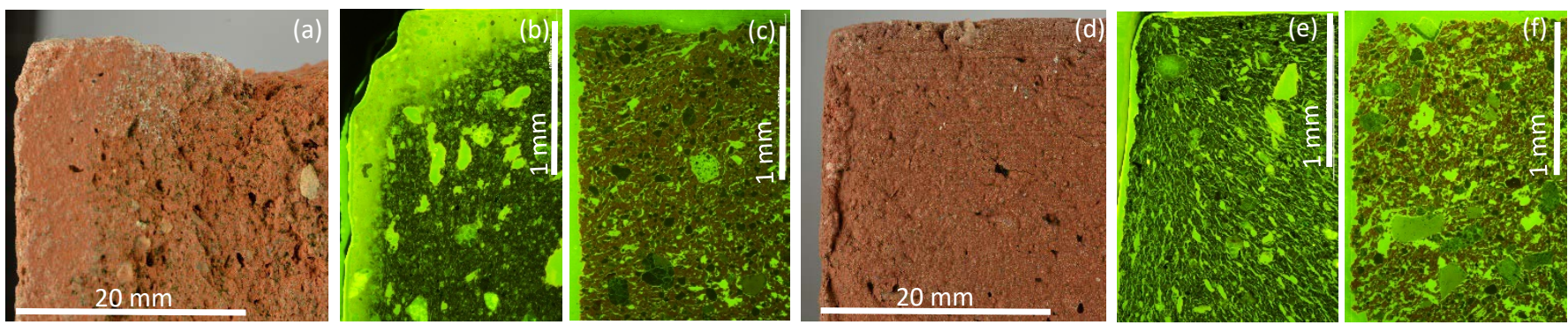

Figure 2. Falkenløwe bright exposed 10 years (FB-10) (a) Macro image of FB-10 (b) FB-10 in fluorescent light (c) FB-R (reference) in fluorescent light; Falkenløwe dark exposed 10 years (FD-10) (d) Macro image of FD-10 e) FD-10 in fluorescent light f) FD-R (reference) in fluorescent light.

* Corresponding author. +45 45252397. ird@byg.dtu.dk

(C) The Author(s). This is an open access article distributed under the terms of the Creative Commons Attribution License (CC BY) 4.0 https:// creativecommons.org/licenses/by/4.0/, which permits unrestricted use, distribution and reproduction in any medium, provided the original author and source are credited. DOI: 10.14293/ICMB210057 


\section{ICMB21}

The measured $\mathrm{pH}$ values for (FB-10) and (FD-10) is shown in Fig. 3. The unfired non-calcareous clay bricks may contain 1 wt\% of calcite $\left(\mathrm{CaCO}_{3}\right)$. During firing, if the temperature exceeds $900^{\circ} \mathrm{C}$, part of the $\mathrm{CaCO}_{3}$ will turn into $\mathrm{CaO}$. In presence of water $\left(\mathrm{H}_{2} \mathrm{O}\right)$, it may turn into $\mathrm{Ca}(\mathrm{OH})_{2}$, and by reaction with carbon dioxide $\left(\mathrm{CO}_{2}\right)$ in the air will turn back to $\mathrm{CaCO}_{3}$. The lower assumed firing temperature for FB may explain its lower reference $\mathrm{pH}$ values as of compared to FD, since a smaller amount of calcite may have turned into calcium oxide and eventually into calcium hydroxide when wetted. The lack of reaction due to lower firing temperature keeps the calcium content mainly as calcium carbonate ( $\mathrm{pH} 9.4$ ) and a rather steady $\mathrm{pH}$ as calcium carbonate is not very soluble. The fluctuating $\mathrm{pH}$ development as a function of depth for FD-10, may result from the combination of larger lumps of calcium carbonate that turned into calcium oxide (confirmed by microscopy) after contact with water. Following this, $\mathrm{CaO}$ may be accessible for $\mathrm{CO}_{2}$ penetration in some areas (lower $\mathrm{pH}$ ), and not in other areas (high $\mathrm{pH}$ ). This tendency is enhanced by larger pores and decreased porosity, resulting from increased firing temperature [4].

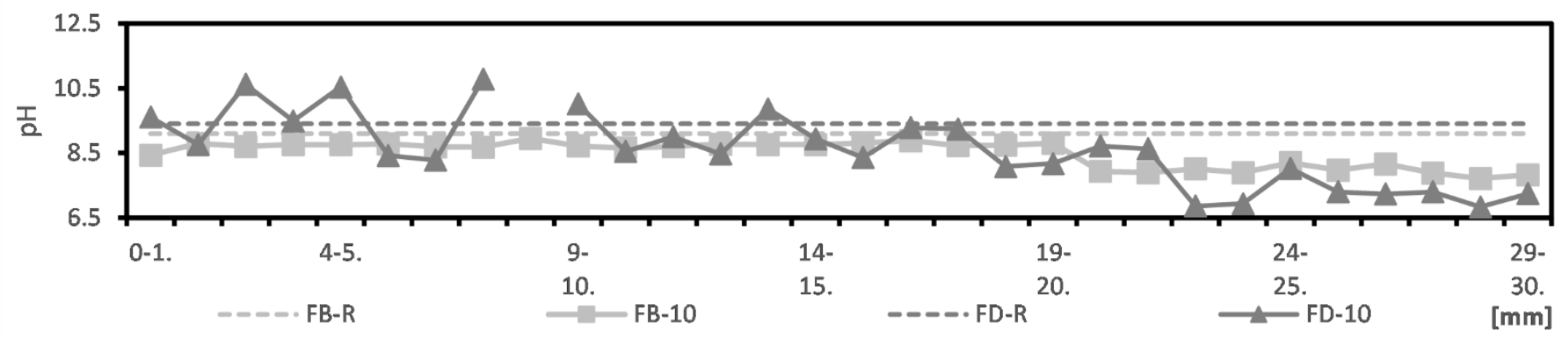

Figure 3. $\mathrm{pH}$ measurements as a function of the distance to the exposed surface.

In the previous study [3], in addition to $\mathrm{pH}$, the silicon content was also found to be a tracer for the evolution of deterioration for fired calcareous bricks. The silicon content for FB-10 and FD-10 is shown in Fig 4. The silicon content reaches a higher and stable content at a depth of 22-23 mm for FD-10, a content similar to that of the reference measured for the brick type "RG", though lower than for the brick type "GF" [3]. It is therefore likely, that aggregates have remained unaffected from the depth of 22-23 mm for FD-10. For FB-10 the silicon content increases with depth, but without reaching a steady content at a level similar to FD-10. Since the two bricks FB-10 and FD-10 are only expected to differ in firing degree, it seems that FB-10 is affected to a depth beyond $30 \mathrm{~mm}$. The $\mathrm{pH}$ values for FB-10 and FD-10 are lower than expected for depths exceeding $22 \mathrm{~mm}$. This might be due to the fact, that firing of the $\mathrm{CaCO}_{2}$ lumps naturally occurring in the clay is less pronounced at these depths when fired in a circular kiln, and might be related more to the $\mathrm{pH}$ of the original clay (around $\mathrm{pH}$ 7); however, this needs to be confirmed.

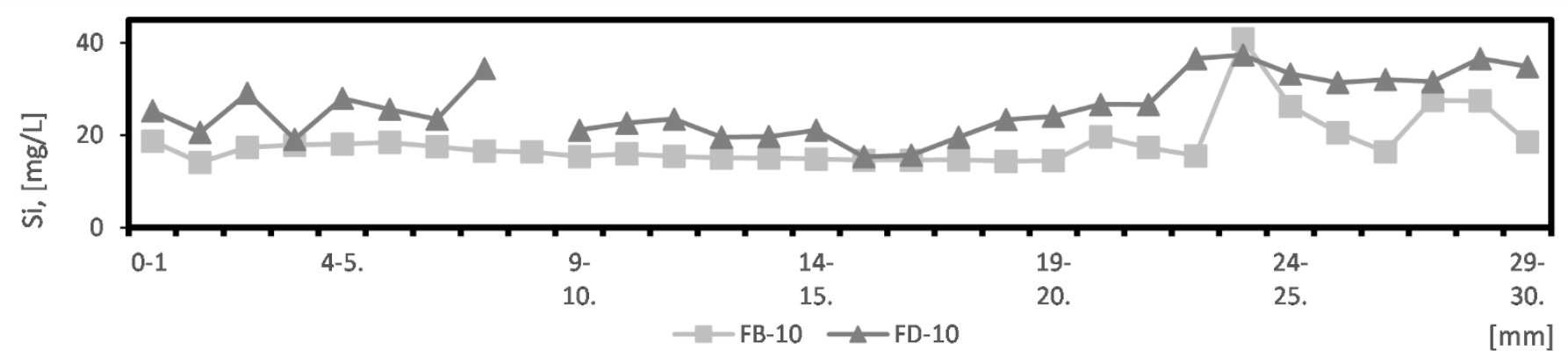

Figure 4. Silicon concentration as a function of the distance to the exposed surface.

\section{Conclusion}

The deterioration depth of extremely weathered, i.e., clearly visible deteriorated, fired non-calcareous bricks, was found by measuring both $\mathrm{pH}$ and silicon contents. The latter is required for greater deterioration depth in these non-homogeneously fired clay bricks, while for more traditional weathering, i.e. no clear visible deterioration, though changed surface appearance, such as discolouring, of calcareous bricks [3], $\mathrm{pH}$ measurements were sufficient to determine deterioration depth.

\section{Acknowledgement}

Martha and Paul Kerrn-Jespersens, The Ramboll and The Cowi Foundations are acknowlegded for finansial support.

\section{Reference}

[1] BYG ERFA blad (21) 190905 Genbrug af mursten - begrcensninger og anvendelsesmuligheder.

[2] EAD (Re-cycled clay masonry units. EAD 170005-00-0305. EOTA).

[3] Rörig-Dalgaard I, Charola A.E (2020). A new method for evaluating the condition of fired clay bricks: preliminary results. In Proceedings of the 14th International Congress on the Deterioration and Conservation of Stone - Volume I and Volume II. Mitteldeutshcer Verlag. Göttingen, Germany.

[4] Rörig-Dalgaard I, Ottosen, L.M.; Hansen K.K. (2012). Diffusion and electromigration in clay bricks influenced by differences in the pore system resulting from firing. Journal of Construction and Building Materials 27 (2012) 390-397.

[5] Tuutti K. (1982). Corrosion of steel in concrete. CBI Forsk. 824. http://lup.lub.lu.se/record/3173286 (accessed June 12, 2020). 